\title{
THE ACTIVITY OF NEURONS IN THE ROSTRAL MEDULLA OF THE RAT DURING WITHDRAWAL FROM NOXIOUS HEAT ${ }^{1}$
}

\author{
H. L. FIELDS, ${ }^{2}$ JOHN BRY, IAN HENTALL, AND GREG ZORMAN \\ Departments of Neurology, Physiology, and Neurosurgery, University of California, San Francisco, California 94143
}

Received April 18, 1983; Revised August 1, 1983; Accepted August 2, 1983

\begin{abstract}
Neurons of the rostral ventromedial medulla (RVM) have been implicated in the modulation of nociceptive transmission. In order to further analyze their role in pain behavior, we studied their activity while eliciting the tail flick reflex with noxious heat.

Recording sites were regions in the RVM from which microstimulation $(\leq 10 \mu \mathrm{A}, 400 \mu \mathrm{sec}, 50 \mathrm{~Hz}$ continuous pulse trains) inhibited the tail flick reflex. Extracellular unit activity and tail temperature were recorded, stored, and plotted with reference to either the time of tail flick or the time when the stimulating temperature reached $45^{\circ} \mathrm{C}$. Neuronal discharges were found to be either increased (on-cells), decreased (off-cells), or unchanged around the time of the tail flick. The decreases in discharge were more closely correlated with the tail flick behavior than with the temperature of the stimulus. These off-cells were located at sites of lowest threshold for tail flick inhibition and tended to be ventral to on-cells.

We propose that off-cells must pause if the tail flick is to occur, and that this pausing allows the transmission of nociceptive input through spinal reflex loops.
\end{abstract}

There is evidence that neurons in the rostral ventromedial medulla (RVM) modulate nociceptor-induced reflexes and the transmission of nociceptive messages (Mayer and Price, 1976; Basbaum and Fields, 1978; Fields and Basbaum, 1978; Gebhart, 1982). RVM neurons receive a major input from the periaqueductal gray (PAG) (Gallager and Pert, 1978; Abols and Basbaum, 1981; Beitz, 1982b), a region implicated in pain modulation and lesions of RVM block analgesia elicited by stimulation of the PAG (Behbehani and Fields, 1979; Cannon et al., 1980). A large number of RVM neurons project to the spinal cord via the dorsolateral funiculus (DLF), terminating primarily in dorsal horn laminae which contain both the terminals of small diameter primary afferents and nociceptive projection neurons (Basbaum et al., 1976, 1977). Electrical stimulation (Oliveras et al., 1975; Zorman et al., 1981) or opiate microinjection (Takagi et al., 1978; Dickenson et al., 1979; Azami et al., 1982 ) in the RVM produces analgesia. Electrical stimulation in the RVM powerfully inhibits nociceptive dorsal horn neurons (Fields et al., 1977b) including identified spinothalamic tract cells (Willis et al., 1977).

\footnotetext{
${ }^{1}$ We thank Drs. S. Lisberger and A. Basbaum for useful discussion of the manuscript. Editorial assistance was provided by Carmen McKee. Research was supported by United States Public Health Service Grant DA 01949.

${ }^{2}$ To whom correspondence should be addressed, at M-794 Neurology, University of California, San Francisco, CA 94143.
}

Despite general agreement about the significance of the RVM for pain modulation, there is evidence that the region is anatomically heterogeneous. In the rat, the RVM consists of the nucleus raphe magnus (NRM), the adjacent nucleus reticularis gigantocellularis pars $\alpha \quad(\operatorname{Rgc} \alpha)$, nucleus reticularis paragigantocellularis (NRPG), and the more lateral nucleus reticularis paragigantocellularis lateralis (Pgl). The efferent outflow of the different subregions of the RVM differ in that NRM neurons project to the spinal cord only via the DLF, whereas Rgc $\alpha$ /NRPG neurons project to the cord in both the DLF and the ventral funiculi (Basbaum et al., 1976; Basbaum and Fields, 1979). Furthermore, there are reports that the analgesic effects of NRM and Pgl stimulation are differentially blocked by 5 -hydroxytryptamine and norepinephrine antagonists, respectively (Satoh et al., 1980; Azami et al., 1982). Initial mapping studies suggested that there are differences in potency of electrical stimulation or opiate microinjection of different subregions of the RVM. Some reported the NRM to be more sensitive (Dickenson et al., 1979), others reported the lateral sites to be more sensitive (Takagi et al., 1978; Azami et al., 1982). In contrast, our own microstimulation studies demonstrated that tail flick inhibition is produced by low intensity electrical stimulation throughout the RVM (Zorman et al., 1981).

Another approach to the functional analysis of RVM neurons has been to record their electrical activity. Early physiological studies in the cat demonstrated that RVM 
neurons respond with either excitation or inhibition, or both, to a variety of somatic stimuli (Moolenaar et al., 1976; Anderson et al., 1977; Fields and Anderson, 1978). In the rat, RVM neurons respond most consistently to stimuli of noxious intensity (Guilbaud et al., 1980; Gebhart, 1982). The response of RVM neurons to noxious stimuli and their well established inhibitory effect upon dorsal horn nociceptors suggest that they are part of a negative feedback circuit for nociceptive control. On the other hand, if such a feedback circuit were reliably excited by nociceptors, it might be expected to inhibit nociceptive transmission and reduce nociceptor-driven reflexes. In fact, such reflexes are present and have identical latency in spinalized (Proudfit and Levy, 1978) and intact rats. Thus, the efferent connections of RVM neurons and their responses to noxious stimuli are not sufficient to establish their physiological role in control of nociceptive transmission.

In order to pursue this question, we have recorded the activity of neurons in regions of the RVM from which low intensity microstimulation induces inhibition of the tail flick reflex. Specifically, we have related cell discharge to the occurrence of the tail flick. Cells either abruptly increased or decreased in discharge frequency just prior to the tail flick (Fields et al., 1982). There was no obvious mediolateral differentiation of cell types; however, the decelerating cells were more ventrally located within the RVM. The hypothesis that decelerating neurons modulate nociceptor-induced neural activity is supported by these results.

\section{Materials and Methods}

Male Sprague-Dawley rats (300 to $350 \mathrm{gm}$ ) were used in all experiments. They were initially anesthetized with $60 \mathrm{mg} / \mathrm{kg}$ of sodium pentobarbital and placed in a stereolaxic apparatus. A burr hole was made and a platinum and gold plated stainless steel electrode was placed about $1 \mathrm{~mm}$ dorsal to the region of the NRPG or the NRM (posterior $2.5 \mathrm{~mm}$ from the interaural line, approximately zero vertical). Body temperature was maintained between 37 and $39^{\circ} \mathrm{C}$ using a constant temperature water blanket.

The ventral surface of the tail was blackened and placed above a projection lamp used as a radiant heat source (opening $6 \times 3 \mathrm{~mm}$ ). A small thermistor probe was placed over the opening so that the tail rested in contact with it. The voltage supplied to the projection lamp was controlled by feedback from the thermistor and by a signal which could be adjusted to vary the stimulus rise time and plateau temperature. A transducer was attached to the tail which provided a voltage pulse when the slightest movement of the tail was made, thus registering the tail flick.

As the initial deep anesthesia lightened, heat elicited a tail flick response at latencies determined both by the rate of temperature rise and the plateau temperature. Pinch with toothed forceps produced withdrawal but no sustained response, no spread of the reflex, and no vocalization or other signs of discomfort. On those occasions when the anesthetic was allowed to lighten even further, rats in ear bars would begin to chew, flex, and show signs of agitation, although, when removed from the ear bars at this anesthetic level, they immediately became immobile. We believe that if additional anesthetic is given at the first sign of spontaneous movement, there is little or no discomfort to the rat during the experiment. Rats could thus be maintained in a state of comfortable light anesthesia with stable base line tail flick latencies, either by constant infusion or by appropriate supplements of sodium pentobarbital.

Once a stable base line tail flick latency was established (4.0 $11 \mathrm{sec})$, electrical stimuli were delivered to the RVM via a stainless steel gold-platinum plated microelectrode (monopolar, cathodal, $50 \mathrm{~Hz}$ continuous trains of $400-\mu$ sec pulses). The stimulus intensity was adjusted to the minimum level needed to just suppress the tail flick reflex. We have previously mapped this region of the medulla with respect to the minimum threshold required for inhibiting the tail flick (Zorman et al., 1981). At the level of the facial nucleus and up to $2 \mathrm{~mm}$ rostral, the lowest threshold points fall within the boundaries of the RVM (roughly the area lying between the facial nuclei, dorsal to the pyramids and ventral to a line connecting the dorsal border of the facial nuclei). In the present studies minimum threshold points were always found within these boundaries. Cell recording was begun at electrode positions from which tail flick inhibition could be obtained at currents of $\leq 10 \mu \mathrm{A}$. Extracellular unit potentials were led through a preamplifier, filters, and window discriminator to a pulse generator. The pulses were led to the computer and audio monitor. Units were recorded both above and below the locus of low threshold tail flick inhibition.

The electrode was advanced with a hydraulic microdrive. When a unit was isolated, its receptive field was quickly mapped using light touch with a blunt probe, puffs of air, and pinching a fold of skin with toothed forceps.

After receptive field mapping, the activity of the unit was correlated with the occurrence of a tail flick using a computer program. Briefly, tail temperature and unit firing (in pulses) were continuously stored for a $20-\mathrm{sec}$ period bracketing the tail flick. The flick-induced voltage pulse generated by the transducer was stored and served as the reference time. After several repetitions of the tail flick, spike probability and mean tail temperature were plotted for 10 sec before and after the flick.

At the end of a penetration the electrode was moved vertically to a point of interest and a small lesion was made. At the end of an experiment, the rat was perfused intracardially with saline and then with $10 \%$ formalin. Frozen sections were cut and stained with neutral red, and penetrations were reconstructed with reference to the lesion depth.

\section{Results}

Only data from units in or near the RVM will be reported. This includes 69 neurons in 13 separate experiments for which complete data on receptive field, brainstem location, and relationship of activity to tail flick are available. Data are included only from penetrations in which a site for low threshold tail flick suppression was found. 


\section{Relationship of firing to tail flick}

In relationship to the occurrence of the tail flick, firing increased in 21 cells either before or roughly concomitant with the onset of the flick ("on-cells") (Fig. 1), decreased in 17 cells prior to the flick ("off-cells") (Fig. 3), and showed no obvious change related to tail flick in the remaining 31 cells (Fig. 5).

On-cells. All on-cells studied were excited by noxious pinch. Noxious stimulation of all skin regions tested was effective. Although some regions appeared more effective than others, the differences in sensitivity were not great. The receptive fields in most cells included all tested areas of the body surface. Innocuous tapping of the skin and hair movement also excited 3 of 20 units tested. These stimuli were effective over all skin regions tested.

There was a spectrum of relationships between cell excitation and occurrence of the tail flick. Usually, the acceleration of discharge was abrupt (Fig. 1), but in three cases it was gradual, suggesting a more direct relationship of the firing to heating the tail.

Seven on-cells were recorded outside the RVM, six were dorsal to NRPG in Rgc (Fig. 6). The remainder (14) were widely distributed within the RVM, at sites generally dorsal to the off-cells (see below and Fig. 6).

Off-cells. Seventeen off-cells were identified. In most cases the slowing of discharge prior to tail movement was abrupt and dramatic (Fig. 2). During a single tail flick trial the cessation of discharge could be detected on the audio monitor. The recovery to base line firing was generally slower than the preceding cessation; frequently, firing remained depressed for several seconds after the flick.

We attempted to discover whether the change in discharge of an off-cell was related more directly to the flick than to heating the tail. The rate of heating and the plateau temperature were adjusted so that the tail flick reflex occurred at a variable latency, although the time course of heating was fairly reproducible. Under these circumstances, the reduction of cell discharge was more

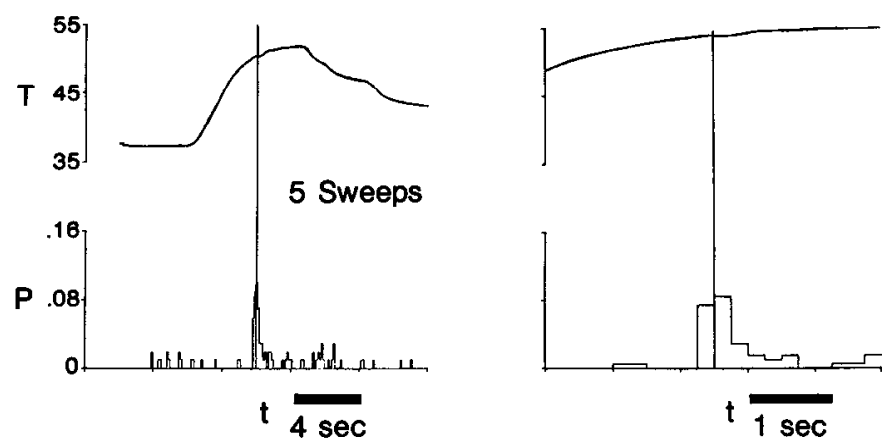

Figure 1. Peri-event histograms of spike probability of an RVM "on-cell" during a heat-elicited tail flick. Spike data are plotted using the occurrence of the tail flick (vertical line) as the reference time. Left, The top trace $(T)$ shows temperature (degrees centigrade) applied to the ventral surface of the tail. The bottom trace $(P)$ shows spike probability per sweep $(250$ msec binwidth). Right, The time scale expanded $200 \mathrm{msec}$ binwidth. To obtain mean discharge frequency at any time, multiply the number of sweeps by the probability and divide by binwidth. There is an abrupt rise preceding the occurrence of a tail flick. abrupt when plotted using the occurrence of the flick as the reference time than when the data were aligned using the temperature increase as the reference time (Fig. 3). This strongly supports the concept that neuronal responses are time-locked to the behavior rather than to the stimulus. Figure $2 B$ is also illustrative. The temperature curve is essentially flat for at least $2 \mathrm{sec}$ before tail flick. The cells' discharge increased slightly or was unchanged until about 400 msec before the tail flick when it abruptly paused. The abruptness of the drop, when averaged over several trials (Figs. 2 and 3), indicates that the latency from the cessation of discharge to the occurrence of tail flick has little variability.

Most off-cells were inhibited by pinching a fold of skin with toothed forceps. These inhibitory responses could be elicited from all areas of the body including head, all paws, trunk, and tail. In two cases noxious cutaneous stimuli were clearly excitatory.

All off-cells were located within the boundaries of the RVM including the NRM, Rgc $\alpha$, NRPG, and Pgl (Fig. $6)$. In all cases, off-cells were recorded at sites where low intensity $(\leq 10 \mu \mathrm{A})$ stimulation resulted in stimulationproduced analgesia (SPA). In six of seven penetrations in which both an on-cell and an off-cell were studied, the off-cell maximum amplitude was recorded ventral to that of the on-cell.

Latency to flick. For six off-cells it was possible to make measurements of the latency between the cessation of discharge and the tail flick. The latency to flick was measured from the time at which the cell's average discharge had fallen to $50 \%$ of its base line level. In the

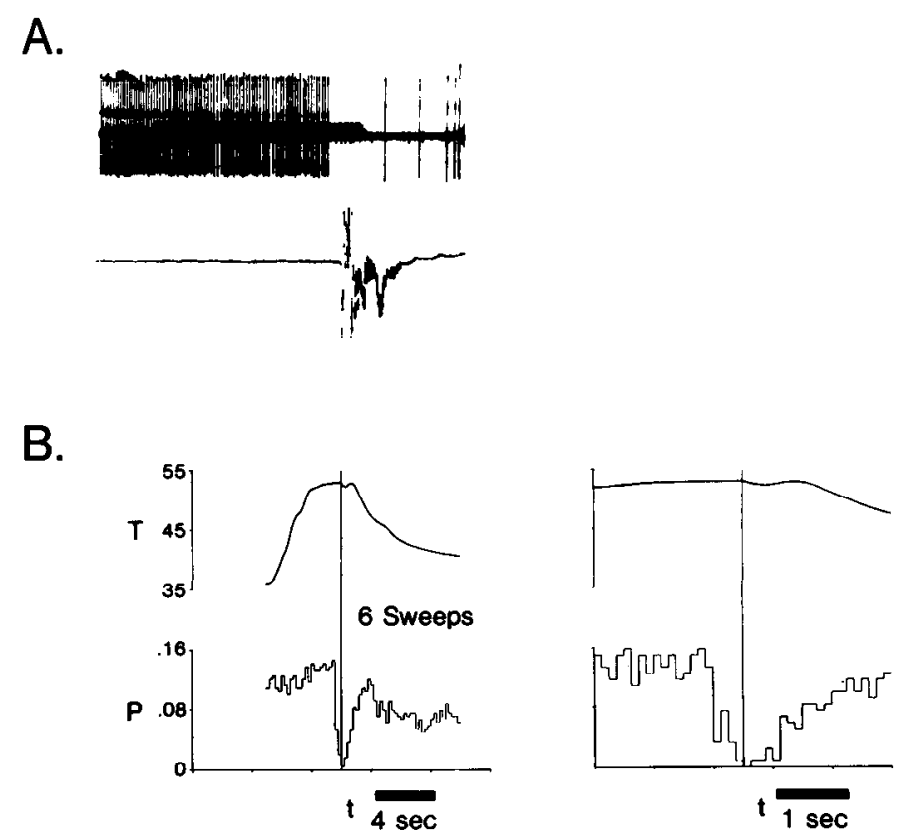

Figure 2. Representative "off-" or "pause-neuron." A, Single sweep illustrating unit action potentials in the upper trace and transducer output on the lower trace. Widening of the base line on the spike trace is an artifact from the heat lamp. Pause before the flick is obvious. $B$, Left: Entire period for which valid data were available. The pause in discharge is abrupt and the recovery is biphasic with a rapid initial phase (binwidth 200 $\mathrm{msec}$ ). Data are the average of six heat trials. Right: Same data with expanded time scale (binwidth $100 \mathrm{msec}$ ). 

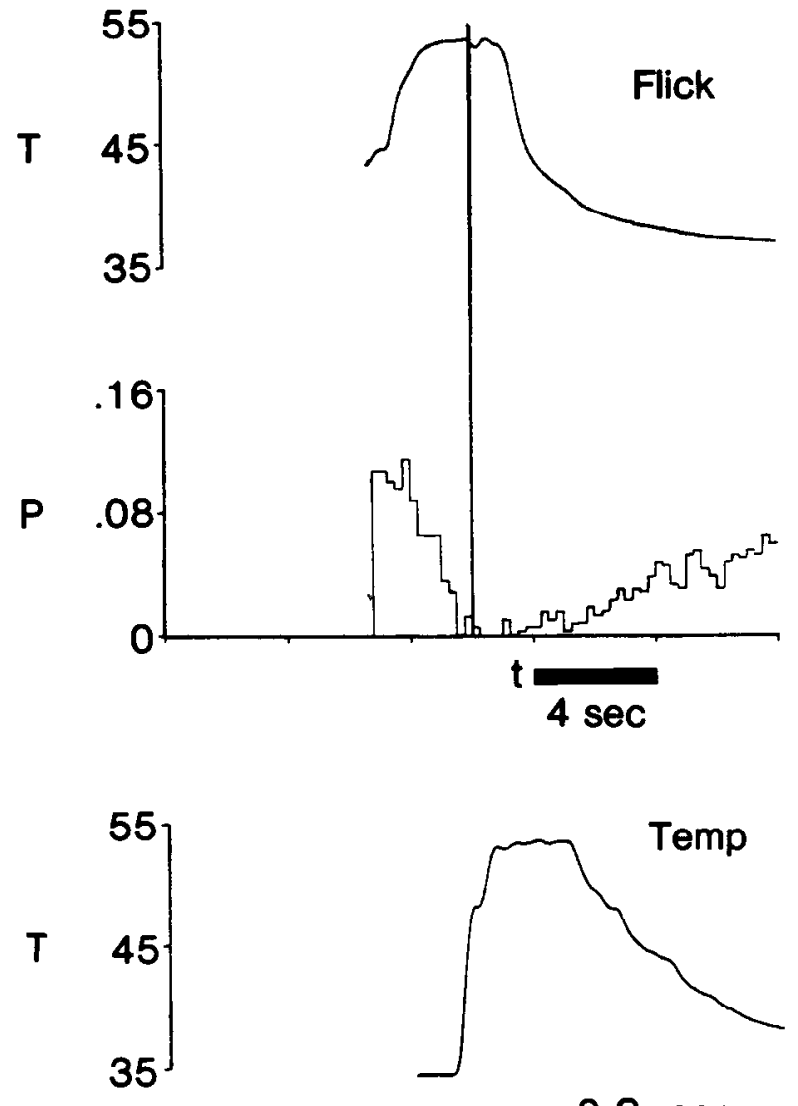

8 Sweeps

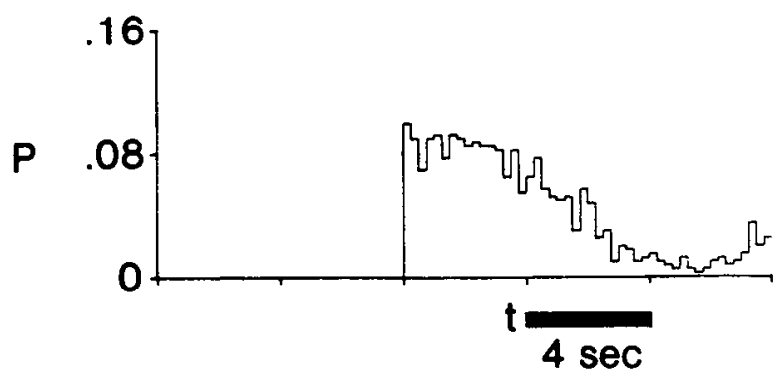

Figure 3. Comparison of off-cell discharge using either temperature or tail flick as reference time. Data were averaged over eight trials. Top (Flick), Representative off-cell with data plotted as in Figures 1 and 2 using the flick as the reference signal ( $250 \mathrm{msec}$ binwidth). Because the flick occurs at a variable time following the temperature rise, the mean temperature curve is broader than in the lower trace. Bottom (Temp), Same spike data replotted using the time when the tail temperature reaches $45^{\circ} \mathrm{C}$ as the reference time. In this case the fall in cell discharge is much more gradual and is incomplete, presumably because the flicks occur at variable latency with respect to temperature.

six cases the cessation of discharge was sufficiently abrupt so that the latencies to flick were easily measured. The mean latency was $450 \pm 87 \mathrm{msec}( \pm$ SD) with a range of 310 to 520 .

\section{Tail flick correlates with cessation of RVM stimulation}

Although the data presented above show that the cessation of discharge in off-cells reliably precedes the tail flick, the data are correlative and do not establish a causal relationship. To provide further evidence on the question of whether cessation of RVM neuronal firing permits tail flick, we did the following experiment using one RVM site in each of five rats. The tail heat stimulator was set to produce a tail flick at our standard latency (3.5 to $4.5 \mathrm{sec}$ ), and was turned on. Simultaneously, a continuous train of stimuli was delivered to the RVM at intensities just above threshold for tail flick inhibition $(6$ to $10 \mu \mathrm{A})$. The stimulus pulse artifacts were fed into the spike channel of the computer. After 10 sec, RVM stimulation was shut off. In all cases, the tail flick occurred within 520 msec after cessation of RVM stimulation (Fig. 4). The mean latency to flick was $385 \pm 54$ msec ( $\pm \mathrm{SD} ; n=5)$. The range of latencies (304 to 512$)$ to flick following cessation of RVM stimulation overlaps the range for latency from off-cell cessation to tail flick onset. Although the mean latencies of the two measurements differ, for this sample size and variance the difference in latencies is not significant.

If a noxious stimulus was not applied to the tail, a tail flick did not follow cessation of RVM stimulation. Conversely, in the presence of noxious heat, tail flick never occurred when suprathreshold RVM stimulus was maintained (up to $30 \mathrm{sec}$ ). Thus, under these experimental conditions, cessation of RVM stimulation is necessary but not sufficient to allow the tail flick to occur.

\section{Cells with discharge not correlated with tail flick}

Of the 31 cells whose discharge did not change significantly prior to tail flick, most (19) had no detectable somatic receptive fields. The remaining 12 all responded maximally to noxious cutaneous stimuli ( 7 excited, 5 inhibited), and 3 also responded to innocuous stimuli. For some, acceleration of discharge occurred shortly after tail flick. There was no clear anatomical segregation of these cells except that the majority (11 of 12) of this category of cells encountered ventral to the off-cells had no somatic inputs and no change in firing with tail flick (Fig. 5).

\section{Discussion}

The present studies have shown that, within the region of the RVM where microstimulation suppresses tail flick, there is a population of neurons whose discharge changes
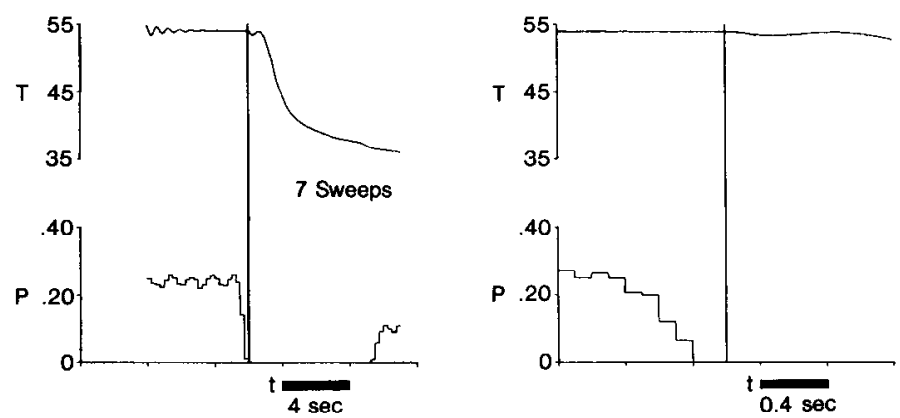

Figure 4. Relationship of tail flick occurrence to cessation of electrical stimulation in the RVM. Upper trace, Temperature applied to tail. Lower trace, Stimulus artifact converted to pulses and entered in the computer as spikes. Left, Usual full time scale (250 msec binwidth). Right, Expanded time scale, $100 \mathrm{msec}$ bins. Heat was applied to the tail during electrical stimulation of the RVM (seven trials). RVM stimulation was shut off and the tail flick occurred (vertical line) approximately 400 msec later. 


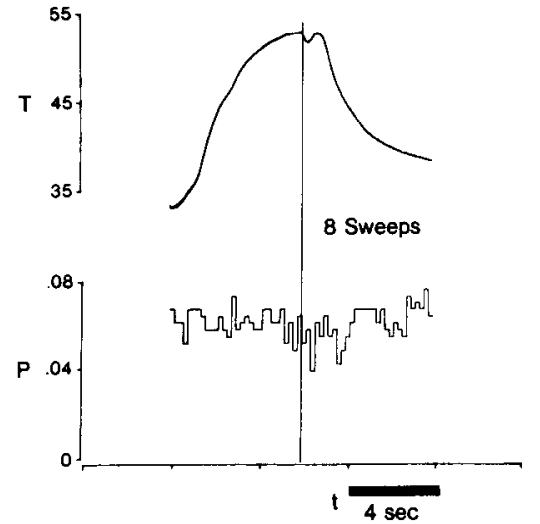

Figure 5. Example of a cell whose discharge is not correlated with tail flick occurrence.

abruptly immediately preceding the occurrence of a tail flick in response to noxious heat. Some of these RVM neurons accelerate (on-cells), others pause (off-cells). The on-cells are excited by noxious stimuli over the rat's entire body surface, whereas the off-cells are generally inhibited by similar stimuli. No obvious segregation of units across the mediolateral axis was observed in these studies (Fig. 6).

Because the noxious stimuli that inhibit the off-cells might produce escape or withdrawal in awake, unanesthetized rats, it is not clear whether the topography of sites from which noxious stimuli produce the on and off responses actually corresponds to a "receptive field" in the same sense as would a similar map for a sensory projection neuron. To answer this question, it would be necessary to record from these cells in awake behaving rats, to see whether the responses occur in the absence of any escape or withdrawal behavior.

As pointed out by previous investigators (see Gebhart, 1982 , for review), the RVM, which has classically been considered to be part of the reticular formation (Brodal, 1981), may be multifunctional, with different subpopulations of neurons in the same region subserving different functions. For example, in addition to the descending projections discussed above, RVM neurons project to areas associated with autonomic function as well as rostrally to the diencephalon (Fields and Basbaum, 1979). Chemical identification of neurons within the RVM has also revealed a great deal of heterogeneity. Serotonin, enkephalin, substance $P$, thyrotropin-releasing hormone, or any combination of these putative transmitters are present in RVM neurons that project to the spinal cord (Hokfelt et al., 1979; Bowker et al., 1981a, b). However, despite this heterogeneity in neuronal populations, there is little spatial segregation of chemically different RVM neurons. It is tempting to speculate that the functionally distinct classes of neurons described in the present report are chemically distinct as well.

Previous reports have focused on the receptive fields of RVM neurons (Gebhart, 1982), without an attempt to relate cell discharge to behavior. Early studies in the cat, specifically designed to survey the NRM, revealed that cells in the region have spatially extensive input from cutancous receptors, both low-threshold mechanoreceptors and nociceptors (Moolenaar et al., 1976; Anderson et al., 1977; Fields and Anderson, 1979). Among more recent studies in the rat there is agreement that a majority of RVM cells are excited by noxious input but that, in addition, a significant percentage are inhibited by noxious stimuli (Behbehani and Pomeroy, 1978; Satoh et al., 1979; Guilbaud et al., 1980). Previous workers found no anatomical segregation between RVM cells that were excited and those that were inhibited by noxious stimuli.

It is not clear how somatosensory input is transmitted to the RVM. Although there is a large spinoreticular projection to the rostral medulla (Mehler, 1969) and spinoreticular cells have large receptive fields with both excitatory and inhibitory nociceptive inputs (Fields et al., 1977a), the NRM and Rgc $\alpha$ receive little direct input from the spinal cord (Gallager and Pert, 1978; Abols and Basbaum, 1981). The more dorsal Rgc, in contrast, does receive a large spinal projection, and it, in turn, projects to the RVM (Beitz, 1982a). The PAG, which is the major input to the RVM, also receives a significant projection from the spinal cord (Beitz, 1982a). Thus, RVM responses to noxious stimuli must involve indirect pathways through the reticular formation, perhaps via Rgc.

The function of the RVM is quite different from that of Rgc. In awake animals, electrical stimulation of Rgc elicits escape behavior (Casey, 1971a, b), whereas RVM stimulation produces analgesia in both awake and lightly anesthetized animals (Oliveras et al., 1975; Zorman et al., 1981). In the rat, Akaike et al. (1978) demonstrated that, within NRPG and $\operatorname{Rgc} \alpha$ but not Rgc, very small doses of microinjected opiates produce analgesia. At a superficial level of analysis, these observations are consistent with the concept that the Rgc functions in part as a sensory nucleus relaying nociceptive input to the thalamus, whereas the RVM is part of a descending system that modulates pain transmission at the level of the spinal cord. The correlation of unit discharge with nociceptor-induced behavior, however, reveals that these designations are inadequate to describe the role of these reticular regions in pain transmission and modulation. For example, Casey (1971a, b) has shown in awake cats that, although the discharge frequency of cells in Rgc increases as a function of peripheral stimulus intensity, in some cases Rgc cell discharge shows a better correlation with escape behavior than with stimulus intensity. Casey concluded that Rgc cells are part of a motivational or decision-making circuit activated by noxious stimuli. More recently, Morrow and Casey (1976) have shown a similar class of cells in rat Rgc whose discharge was correlated with tail flick.

In the present studies of RVM neurons, it is also clear that the changes in discharge frequency consequent to noxious stimuli are not a simple function of stimulus intensity but, in fact, herald a behavioral change. However, as discussed above, the evidence indicates that, in contrast to Rgc which elicits escape behavior, RVM neurons inhibit nociceptor-induced behavior.

Although it is not possible at this point to say what the on-cells and off-cells each contribute to modulation of nociception, several observations are pertinent to the interpretation of their location and discharge pattern. Off-cells are more restricted in their distribution; none were found in Rgc and all were near sites of minimum SPA threshold. In contrast, on-cells have a more dorsal 

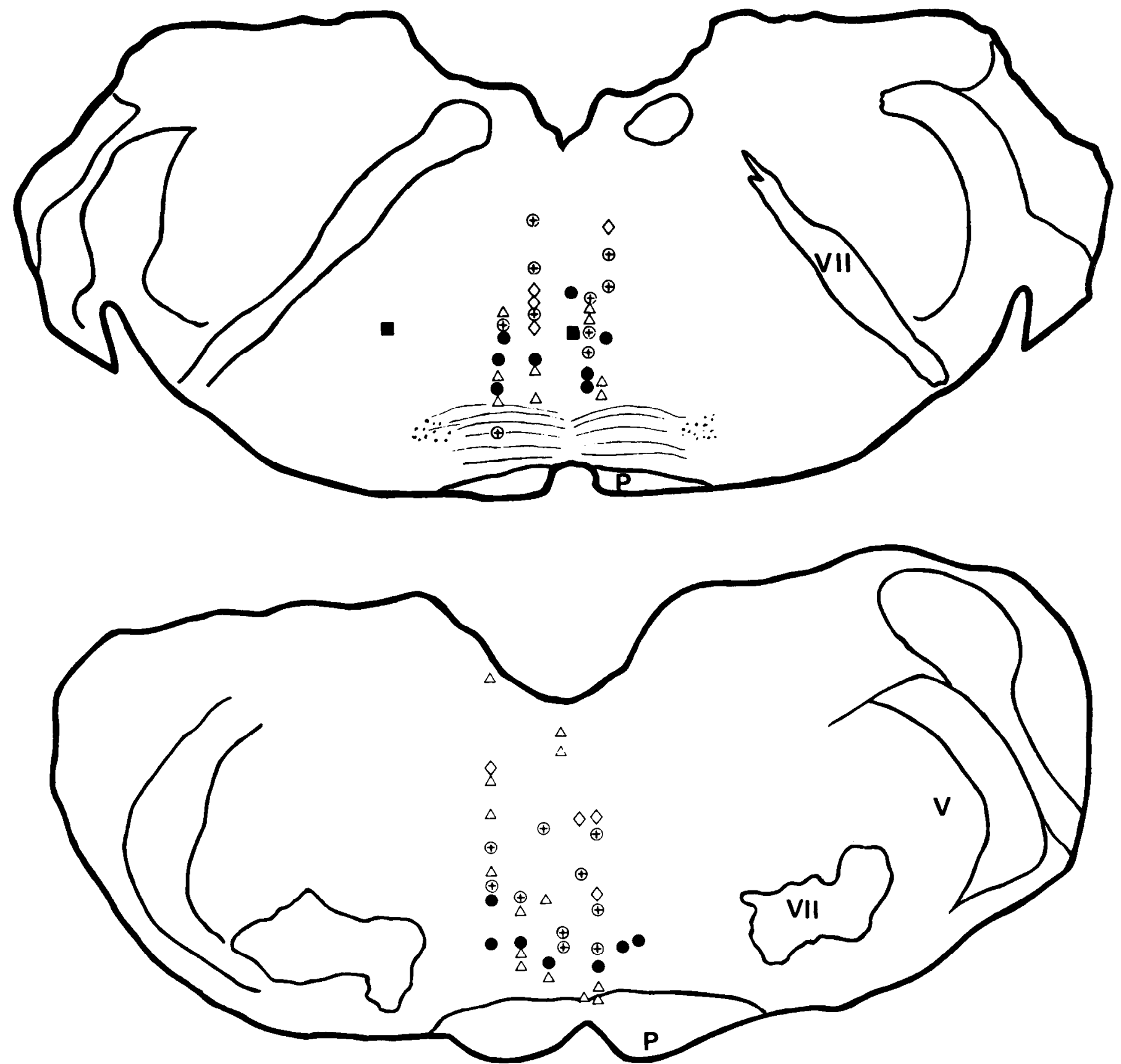

Figure 6. Schematic reconstruction of the locations of peak amplitudes of recorded cells. Locations are plotted on two representative sections of the rostral medulla. $\oplus$, on-cell with excitatory receptive field; $\boldsymbol{\bullet}$, off-cell with inhibitory receptive field; $\square$, off-cell with excitatory receptive field; $\Delta$, cell with no receptive field, discharge unrelated to tail flick; $\diamond$, cell with receptive field, discharge unrelated to tail flick. $P$, pyramidal tract; VII, facial nerve and nucleus; $V$, spinal trigeminal nucleus.

distribution and some are located in Rgc, away from the most sensitive SPA sites. These observations suggest that the off-cells may be the effectors of tail flick inhibition. Assuming that the off-cells must pause for the tail flick to occur, electrical stimulation of the RVM might prevent the tail flick by artificially preventing the pause. This conclusion is supported by the observation that, during noxious stimulation of the tail, cessation of low intensity electrical stimulation of the RVM is rapidly followed by the tail flick at a latency similar to the latency from cessation of off-cell discharge to tail flick.

We have recently shown, using antidromic activation, that all classes of RVM cells project to the spinal cord (Vanegas et al., 1983). Thus there is a direct pathway by which off-cells can inhibit spinal nociceptive transmission, although this does not exclude a role for other classes of RVM cells. Further evidence implicating the off-cells in analgesia is that morphine concomitantly blocks the tail flick and the off-cell pause (Zorman et al., 1983).

A class of neuron with properties similar to those of the off-cell has been described in studies of the oculomotor system (Keller, 1974; Evinger et al., 1982). These cells, the omnipause neurons, are clustered just rostral 
to the abducens nucleus on or near the midline. The firing of omnipause neurons ceases abruptly just prior to a saccadic eye movement. Electrical microstimulation in the omnipause region will either prevent or interrupt a saccade. Thus, both oculomotor omnipause cells and the off-cells described in the present study provide a mechanism for inhibiting phasic movements. The circuitry that generates the pause in either cell is not known, although it is clearly related to the signal that generates the movement.

The role of the on-cell is not clear, but some possibilities are very unlikely. First, since the tail flick is a reflex that occurs at a similar latency in intact and spinal rat, it is unlikely that the on-cell directly drives the reflex (although there are direct connections from this region of the medulla to the ventral horn of the spinal cord). The fact that stimulation in the RVM or Rgc does not produce tail movements also supports this conclusion. However, it is possible that, in the awake rat, on-cell activation is correlated with more complex escape behavior. On cells seem unlikely to inhibit the tail flick since an increase in their discharge precedes the occurrence of the flick, although, conceivably, by inhibiting an inhibitory neuron in the cord, they could "permit" the reflex in the same way as the cessation of the off-cell. On-cells could act to enhance spinal withdrawal reflexes or could be part of an ascending pathway and thus functionally related to the cells in Rgc that Casey (1971a, b) studied. Another possibility is that on-cells act locally to inhibit off-cells.

Handwerker and Sack (1982) have described cells in the PAG that are similar to the on-cells described here. Although these authors also proposed that, in some cases, the cell responses they observed were more closely related to tail flick than to the noxious heat stimulus, the acceleration in discharge they demonstrated was gradual and began several seconds before the flick.

In summary, the present data, which combine the study of sensory input to a neuron with its activity during the behavior elicited by that input, are consistent with the concept of a modulatory as opposed to either a strictly motor or sensory relay function for neurons in the RVM. There are two types of cells with opposite firing patterns. The off-cell appears to be the output modulator. The function of the on-cell remains obscure.

\section{References}

$\Lambda$ bols, I. $\Lambda$., and A. I. Basbaum (1981) Afferent connections of the rostral medulla of the cat: A neural substrate for midbrain-medullary interactions in the modulation of pain. J. Comp. Neurol. 201: 285-297.

Akaike, A., T. Shibata, M. Satoh, and K. Takagi (1978) Analgesia induced by microinjection of morphine into, and electrical stimulation of, the nucleus reticularis paragigantocellularis of rat medulla oblongata. Neuropharmacology 67: 775778.

Anderson, S. D., A. I. Basbaum, and H. L. Fields (1977) Response of medullary raphe neurones to peripheral stimulation and to systemic opiates. Brain Res. 123: 363-368.

Azami, J., M. D. Llewelyn, and M. H. T. Roberts (1982) The contribution of nucleus reticularis paragigantocellularis and nucleus raphe magnus to the analgesia produced by systemically administered morphine, investigated with the microinjection technique. Pain 12: 229-246.

Basbaum, A. I., and H. L. Fields (1978) Endogenous pain control mechanisms: Review and hypothesis. Ann. Neurol. 4: 451-462.

Basbaum, A. I., and H. L. Fields (1979) The origin of descending pathways in the dorsal lateral funiculus of the spinal cord of the cat and rat: Further studies on the anatomy of pain modulation. J. Comp. Neurol. 187: 513-532.

Basbaum, A. I., C. H. Clanton, and H. L. Fields (1976) Opiate and stimulus-produced analgesia: Functional anatomy of a medullospinal pathway. Proc. Natl. Acad. Sci. U. S. A. 73: 4685-4688.

Basbaum, A. I., C. H. Clanton, and H. L. Fields (1977) Three bulbospinal pathways from the rostral medulla of the cat. An autoradiographic study. J. Comp. Neurol. 128: 209-224.

Behbehani, M. M., and H. L. Fields (1979) Evidence that excitatory connections between the periaqueductal gray and nucleus raphe magnus mediate stimulation produced analgesia. Brain Res. 170: 85-93.

Behbehani, M. M., and S. L. Pomeroy (1978) Effect of morphine in periaqueductal gray on the activity of single units in the nucleus raphe magnus of the rat. Brain Res. 149: 266269.

Beitz, A. J. (1982a) The sites of origin of brain stem neurotensin and serotonin projections to the rodent nucleus raphe magnus. J. Neurosci. 2: 829-842.

Beitz, A. J. (1982b) The organization of afferent projections to the mid-brain periaqueductal gray of the rat. Neuroscience 7: 133-159.

Brodal, A. (1981) Neurologial Anatomy in Relation to Clinical Medicine, Ed. 3, Oxford University Press, New York.

Bowker, R. M., H. W. M. Steinbusch, and J. D. Coulter (1981a) Serotonergic and peptidergic projections to the spinal cord demonstrated by a combined retrograde HRP histochemical and immunohistochemical staining method. Brain Res. 211: 412-417.

Bowker, R. M., K. N. Westlund, and J. D. Coulter (1981b) Origins of serotonergic projections to the spinal cord in rat: An immunocytochemical retrograde transport study. Brain Res. 226: 187-199.

Cannon, J. T., G. J. Prieto, and J. C. Liebeskind (1980) Disruption of stimulation produced analgesia by lesions of the nucleus raphe magnus. Soc. Neurosci. Abstr. 6: 320 .

Casey, K. L. (1971a) Somatosensory response of bulboreticular units in awake cat: Relation to escape producing stimuli. Science 173: 77-80.

Casey, K. L. (1971b) Escape elicited by bulboreticular stimulation in the cat. Int. J. Neurosci. 2: 29-34.

Dickenson, A. K., J. L. Oliveras, and J. M. Besson (1979) Role of the nucleus raphe magnus in opiate analgesia as studied by the microinjection technique in the rat. Brain Res. 170: 95-111.

Evinger, C., C. R. S. Kaneko, and A. F. Fuchs (1982) Activity of omnipause neurons in alert cats during saccadic eye movements and visual stimuli. J. Neurophysiol. 47: 827-844.

Fields, H. L., and S. D. Anderson (1978) Evidence that raphespinal neurons mediate opiate and midbrain stimulation produced analgesia. Pain 5: 333-350.

Fields, H. L., and A. I. Basbaum (1978) Brainstem control of spinal pain transmission neurons. Annu. Rev. Physiol. 40: 217-248.

Fields, H. L., and A. I. Basbaum (1979) Anatomy and physiology of a descending pain control system. In Advances in Pain Research and Therapy, D. Albe-Fessard and J. J. Bonica, eds., Vol. 3, pp. 427-440, Raven Press, New York.

Fields, H. L., C. H. Clanton, and S. D. Anderson (1977a) Somatosensory properties of spinoreticular neurons in the cat. Brain Res. 120: 49-66.

Fields, H. L., A. I. Basbaum, C. H. Clanton, and S. D. Anderson (1977b) Nucleus raphe magnus inhibition of spinal cord dorsal horn neurons. Brain Res. 126: 441-454. 
Fields, H. I.., I. D. Hentall, and G. Zorman (1982) Two classes of neurons in analgesia-producing regions of the rostralventromedial medulla. Soc. Neurosci. Abstr. 8: 806.

Gallager, D. W., and A. Pert (1978) Afferents to brain stem nuclei (brain stem raphe, nucleus reticularis pontis candalis and nucleus gigantocellularis) in the rat as demonstrated by microiontophoretically applied horseradish peroxidase. Brain Res. 144: 257-275.

Gebhart, G. F. (1982) Opiate and opioid peptide effects on brain stem neurons: Relevance to nociceptor and antinociceptor mechanisms. Pain 12: 93-140.

Guilbaud, G., M. Peschanski, M. Gautron, and O. Binder (1980) Responses of neurons of the nucleus raphe magnus to noxious stimuli. Neurosci. Lett. 17: 149-154.

Handwerker, H. O., and R. Sack (1982) Single unit activity in the rat's midbrain during nocifensive tail flick reaction. Neurosci. Lett. 30: 79-84.

Hokfelt, T., L. Terenius, H. G. J. M. Kuypers, and O. Dann (1979) Evidence for enkephalin immunoreactive neurons in the medulla oblongata projecting to the spinal cord. Neurosci. Lett. 4: 55-60.

Keller, E. L. (1974) Participation of medial pontine reticular formation in eye movement generation in monkey. J. Neurophysiol. 37: 316332 .

Mayer, D. J., and D. D. Price (1976) Central nervous system mechanisms of analgesia. Pain 2: 379-404.

Mehler, W. (1969) Some neurological species differences-A posteriori. Ann. N. Y. Acad. Sci. 167: 424-468.

Moolenaar, G. M., J. A. Holloway, and C. D. Trouth (1976) Responses of caudal raphe neurones to peripheral somatic stimulation. Exp. Neurol. 53: 304-313.

Morrow, 'T. J., and K. L. Casey (1976) Analgesia produced by mesencephalic stimulation: Effect on bulboreticular neurons. In Advances in Pain Research and Therapy, D. Albe-Fessard and J. J. Bonica, eds., Vol. 1, pp. 503-516, Raven Press, New York.
Oliveras, J. L., F. Redjemi, G. Guilhaud, and J. M. Besson (1975) Analgesia induced by electrical stimulation of the inferior centralis nucleus of the raphe of the cat. Pain 1:139145.

Proudfit, H. K., and R. A. Levy (1978) Delimitation of neuronal substrates necessary for the analgesic action of baclofen and morphine. Eur. J. Pharmacol. 47: 159-168.

Ruda, M. A. (1975) An autoradiographic study of the efferent projections of the midbrain central gray in the cat. Anat. Rec. 181: 468.

Satoh, M., A. Akaike, and H. Takagi (1979) Excitation by morphine and enkephalin of single neurons of the nucleus reticularis paragigantocellularis in the rat: A probable mechanism of analgesic action of opioids. Brain Res. 169: 406410 .

Satoh, M., A. Akaike, T. Nakazawa, and H. Takagi (1980) Evidence for involvement of separate mechanisms in the production of analgesia by electrical stimulation of the nucleus reticularis paragigantocellularis and nucleus raphe magnus in the rat. Brain Res. 194: 525-529.

Takagi, H., M. Satoh, A. Akaike, T. Shibata, and H. Yajima (1978) Analgesia by enkephalins injected into the nucleus reticularis gigantocellularis of the rat medulla oblongata. Eur. J. Pharmacol. 49: $113 \cdots 116$.

Vanegas, H., N. M. Barbaro, and H. L. Fields (1983) Activity of raphe-spinal (DLF) neurons in relation to nocifensive behavior. Soc. Neurosci. Abstr. 9: 3.

Willis, W. D., L. H. Haber, and R. F. Martin (1977) Inhibition of spinothalamic tract cells and interneurons by brain stem stimulation in the monkey. J. Neurophysiol. 40: 968-981.

Zorman, G., I. D. Hentall, J. E. Adams, and H. L. Fields (1981) Naloxone-reversible analgesia produced by microstimulation in the rat medulla. Brain Res. 219: 137-148.

Zorman, G., H. Vanegas, I. Hentall, and H. Fields (1983) Evidence that morphine produces analgesia by disinhibiting brainstem neurons. Soc. Neurosci. Abstr. 9: 3 . 